NASA/TM-2003-212079

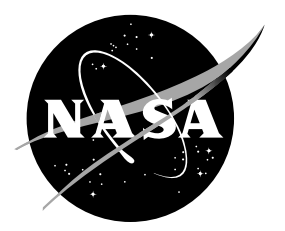

\title{
Electronic Components and Circuits for Extreme Temperature Environments
}

Richard L. Patterson

Glenn Research Center, Cleveland, Ohio

Ahmad Hammoud

QSS Group, Inc., Cleveland, Ohio

John E. Dickman

Glenn Research Center, Cleveland, Ohio

Scott Gerber

ZIN Technologies, Inc., Cleveland, Ohio 
Since its founding, NASA has been dedicated to the advancement of aeronautics and space science. The NASA Scientific and Technical Information (STI) Program Office plays a key part in helping NASA maintain this important role.

The NASA STI Program Office is operated by Langley Research Center, the Lead Center for NASA's scientific and technical information. The NASA STI Program Office provides access to the NASA STI Database, the largest collection of aeronautical and space science STI in the world. The Program Office is also NASA's institutional mechanism for disseminating the results of its research and development activities. These results are published by NASA in the NASA STI Report Series, which includes the following report types:

- $\quad$ TECHNICAL PUBLICATION. Reports of completed research or a major significant phase of research that present the results of NASA programs and include extensive data or theoretical analysis. Includes compilations of significant scientific and technical data and information deemed to be of continuing reference value. NASA's counterpart of peerreviewed formal professional papers but has less stringent limitations on manuscript length and extent of graphic presentations.

- TECHNICAL MEMORANDUM. Scientific and technical findings that are preliminary or of specialized interest, e.g., quick release reports, working papers, and bibliographies that contain minimal annotation. Does not contain extensive analysis.

- CONTRACTOR REPORT. Scientific and technical findings by NASA-sponsored contractors and grantees.
- CONFERENCE PUBLICATION. Collected papers from scientific and technical conferences, symposia, seminars, or other meetings sponsored or cosponsored by NASA.

- SPECIAL PUBLICATION. Scientific, technical, or historical information from NASA programs, projects, and missions, often concerned with subjects having substantial public interest.

- TECHNICAL TRANSLATION. Englishlanguage translations of foreign scientific and technical material pertinent to NASA's mission.

Specialized services that complement the STI Program Office's diverse offerings include creating custom thesauri, building customized databases, organizing and publishing research results ... even providing videos.

For more information about the NASA STI Program Office, see the following:

- Access the NASA STI Program Home Page at http://www.sti.nasa.gov

- E-mail your question via the Internet to help@sti.nasa.gov

- Fax your question to the NASA Access Help Desk at 301-621-0134

- Telephone the NASA Access Help Desk at 301-621-0390

- Write to:

NASA Access Help Desk

NASA Center for AeroSpace Information 7121 Standard Drive

Hanover, MD 21076 
NASA/TM-2003-212079

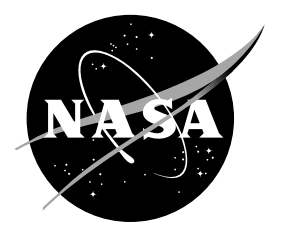

\section{Electronic Components and Circuits for Extreme Temperature Environments}

Richard L. Patterson

Glenn Research Center, Cleveland, Ohio

Ahmad Hammoud

QSS Group, Inc., Cleveland, Ohio

John E. Dickman

Glenn Research Center, Cleveland, Ohio

Scott Gerber

ZIN Technologies, Inc., Cleveland, Ohio

Prepared for the

2003 Aerospace Conference

sponsored by the Institute of Electrical and Electronics Engineers

Big Sky, Montana, March 8-15, 2003

National Aeronautics and

Space Administration

Glenn Research Center 
This report is a formal draft or working paper, intended to solicit comments and ideas from a technical peer group.

This report contains preliminary findings, subject to revision as analysis proceeds.

This report is a preprint of a paper intended for presentation at a conference. Because of changes that may be made before formal publication, this preprint is made available with the understanding that it will not be cited or reproduced without the permission of the author.

Available from

NASA Center for Aerospace Information 7121 Standard Drive

Hanover, MD 21076
National Technical Information Service 5285 Port Royal Road Springfield, VA 22100 


\section{Electronic Components and Circuits for Extreme Temperature Environments}

\author{
Richard L. Patterson \\ National Aeronautics and Space Administration \\ Glenn Research Center \\ Cleveland, Ohio 44135 \\ Ahmad Hammoud \\ QSS Group, Inc. \\ Cleveland, Ohio 44135
}

\author{
John E. Dickman \\ National Aeronautics and Space Administration \\ Glenn Research Center \\ Cleveland, Ohio 44135 \\ Scott Gerber \\ ZIN Technologies, Inc. \\ Cleveland, Ohio 44135
}

TABLE OF CONTENTS

Planetary exploration missions and deep space probes require electrical power management and control systems that are capable of efficient and reliable operation in very low temperature environments. Presently, spacecraft operating in the cold environment of deep space carry a large number of radioisotope heating units in order to maintain the surrounding temperature of the on-board electronics at approximately $20^{\circ} \mathrm{C}$. Electronics capable of operation at cryogenic temperatures will not only tolerate the hostile environment of deep space but also reduce system size and weight by eliminating or reducing the radioisotope heating units and their associate structures; thereby reducing system development as well as launch costs. In addition, power electronic circuits designed for operation at low temperatures are expected to result in more efficient systems than those at room temperature. This improvement results from better behavior and tolerance in the electrical and thermal properties of semiconductor and dielectric materials at low temperatures.

The Low Temperature Electronics Program at the NASA Glenn Research Center focuses on research and development of electrical components, circuits, and systems suitable for applications in the aerospace environment and deep space exploration missions. Research is being conducted on devices and systems for reliable use down to cryogenic temperatures. Some of the commercial-off-theshelf as well as developed components that are being characterized include switching devices, resistors, magnetics, and capacitors. Semiconductor devices and integrated circuits including digital-to-analog and analog-todigital converters, DC/DC converters, operational amplifiers, and oscillators are also being investigated for potential use in low temperature applications. An overview of the NASA Glenn Research Center Low Temperature Electronic Program will be presented in this paper. A description of the low temperature test facilities along with selected data obtained through in-house component and circuit testing will also be discussed. Ongoing research activities that are being performed in collaboration with various organizations will also be presented.
1. INTRODUCTION $\ldots \ldots \ldots \ldots \ldots \ldots \ldots \ldots \ldots \ldots \ldots \ldots \ldots \ldots \ldots$

2. NASA GRC LOW TEMPERATURE ELECTRONICS

Program................................... 2

3. GRC LOW TEMPERATURE FACILITIES .......... 2

4. LOW TEMPERATURE R\&D ACTIVITIES ........ 3

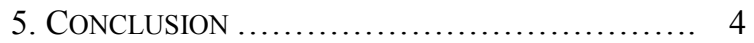

REFERENCES $\ldots \ldots \ldots \ldots \ldots \ldots \ldots \ldots \ldots \ldots \ldots \ldots \ldots, 4$

\section{INTRODUCTION}

Electronic components and systems capable of low temperature operation are required for many future NASA space missions where it is desirable to have smaller, lighter, and cheaper spacecraft. These include Mars orbiters, landers, and rovers; Europa oceanic exploratory instrumentation; and outer planetary exploration and deep space probes. Table 1 shows operational temperatures for unheated spacecraft in the environments of the outer planets. For example, an inter-planetary probe launched to explore the rings of Saturn would experience a temperature near Saturn of about $-183^{\circ} \mathrm{C}$.

Presently, spacecraft operating in the cold environment of deep space carry on-board a large number of radioisotope heating units (RHUs) to maintain an operating temperature for the electronics of approximately $20^{\circ} \mathrm{C}$ [1]. This is not an ideal solution because the radioisotope heating units are always producing heat, even when the spacecraft may already be too hot, thus requiring an active thermal control system for the spacecraft. In addition, RHUs are very expensive and require elaborate containment structures. Electronics capable of operation at cryogenic temperatures will not only tolerate the hostile environment of deep space but also reduce system size and weight by eliminating radioisotope heating units and associated structures; thereby reducing system development and launch costs, improving reliability and lifetime, and increasing energy densities. 
Table 1: Typical Operational Temperatures for Unheated Spacecraft

\begin{tabular}{|l|c|}
\hline Mission & Temperature, ${ }^{\circ} \mathrm{C}$ \\
\hline Mars & -20 to -120 \\
\hline Jupiter & -151 \\
\hline Saturn & -183 \\
\hline Uranus & -209 \\
\hline Neptune & -222 \\
\hline Pluto & -229 \\
\hline
\end{tabular}

In addition to deep space applications, low temperature electronics have potential uses in terrestrial applications that include magnetic levitation transportation systems, medical diagnostics, cryogenic instrumentation, and superconducting magnetic energy storage systems. The utilization of power electronics designed for and operated at low temperature is expected to result in more efficient systems than room temperature systems. This improvement results from better electronic, electrical, and thermal properties of materials at low temperatures $[2,3]$. In particular, the performance of certain semiconductor devices improves with decreasing temperature down to liquid nitrogen temperature $\left(-196^{\circ} \mathrm{C}\right)[3,4]$. At low temperatures, majority carrier devices demonstrate reduced leakage current and reduced latch-up susceptibility. In addition, these devices show higher speed resulting from increased carrier mobility and saturation velocity [3-5]. An example is the power MOSFET that has lower conduction losses at low temperature due to the reduction in the drain-to-source resistance $\mathrm{RDS}(\mathrm{on})$ resulting from increased carrier mobility $[4,6,7]$.

\section{NASA GLENN RESEARCH CENTER LOW TeMPERATURE ElECTRONICS PROGRAM}

The Low Temperature Electronics Program at the NASA Glenn Research Center (GRC) focuses on research and development of electrical components and systems suitable for applications in deep space missions. Research is being conducted on devices and systems for use down to cryogenic temperature. The goal of the low temperature electronics program is to develop and demonstrate reliable, efficient, power systems capable of surviving and exploiting the advantages of low temperature environments. The targeted systems are mission-driven and include converters, inverters, controls, digital circuits, and special-purpose circuits. Initial development efforts have produced the successful demonstration of low temperature operation and cold-restart of several DC/DC converters (with outputs from 5 to 1000 Watts) utilizing different design topologies $[1,4,7]$. Some of these circuits employed superconducting inductors.

In support of system development, device and component research and development efforts are underway in critical areas of passive and active components, optoelectronic devices, and energy generation and storage. Initially, commercial-off-the-shelf (COTS) devices and components are characterized in terms of their performance at lowtemperatures. When viable commercial devices fail to meet mission requirements, efforts are then undertaken to develop advanced components. In addition to the development efforts to fill the technology gaps in low temperature power electronics, thermal issues relating to packaging, integration, and cycling are being explored.

\section{GRC LOW TEMPERATURE FACILITIES}

At NASA Glenn Research Center, facilities exist for the testing of power and control circuits operating from DC to several Megahertz over a wide temperature range. These facilities consist of several liquid nitrogen cooled environmental chambers in which a circuit can be operated with controlled temperature in the range of $300{ }^{\circ} \mathrm{C}$ to $-196{ }^{\circ} \mathrm{C}$. The chambers have built-in controllers that allow selecting the desired temperature rate of change as well as soak times. Computer-controlled instrumentation is interfaced with the environmental chambers via IEEE GPIB-488 for data acquisition. Measurement equipment include a digital signal analyzer, pattern generators, precision digital RLC meters, high speed storage oscilloscopes, precision temperature controller and recorder, various electronic loads, and resistive loads from $\mathrm{mW}$ 's to $\mathrm{kW}$ 's in power.

A unique computerized control system is used in conjunction with a cryopumped vacuum chamber containing a cryocooled sample holder for the characterization of commercial and developmental semiconductor devices and components. This facility is capable of in-situ $\mathrm{I}-\mathrm{V}$ and $\mathrm{C}-\mathrm{V}$ characterization of semiconductor devices from $23{ }^{\circ} \mathrm{C}$ to $-248^{\circ} \mathrm{C}$

GRC has also designed computer-controlled facilities for low-temperature long term thermal cycling and characterization of electrical and physical properties of dielectrics and capacitors. In addition, facilities have been built at GRC for reliability studies and life testing of passive and active devices in space-like environments under multistress conditions. Typical studies that can be carried out using these unique facilities include dielectric material characterization, DC and AC breakdown voltages, resistivity measurements, switching characteristics, and electronic system overall performance such as regulation and efficiency.

In the area of optoelectronics, GRC has facilities to characterize and test fiber-optic sources, receivers, cables, connectors, and other components and assemblies at temperatures from $300{ }^{\circ} \mathrm{C}$ to $-196{ }^{\circ} \mathrm{C}$. Although most low temperature testing on fiber-optic components has concentrated on $1300 \mathrm{~nm}$ to date, tests can be conducted at other wavelengths.

Other on-site supporting research facilities include physical, chemical, and mechanical test chambers and diagnosis stations. Characterization of materials and evaluation of systems and components under space-like environment, such as vacuum, plasma, ultraviolet radiation, and atomic oxygen, can be achieved in multi-stress aging test rigs and facilities. 


\section{LOW TEMPERATURE R\&D ACTIVITIES}

Some of the components that are being characterized include semiconductor switching devices, pulse width modulation controllers, high frequency oscillators, $\mathrm{dc} / \mathrm{dc}$ converters, sensors and transducers, and passive and active devices, to name a few.

Figure 1 shows the performance of a military-grade pulse width modulation (PWM) controller at various temperatures. The effect of temperature on duty cycle of the device at various control voltage levels is depicted in this figure. This BiCMOS current-mode PWM device, which is rated for -55 to $+125{ }^{\circ} \mathrm{C}$ operation, was characterized at a switching frequency of $100 \mathrm{kHz}$. It can be seen that at room temperature, the maximum duty cycle obtained was $95 \%$ at a control voltage level of $1.7 \mathrm{~V}$. Upon lowering the test temperature, the value of the control voltage level required to obtain a specific duty cycle decreased significantly. For example, the values of this signal required for a $50 \%$ output duty cycle were about $1.4 \mathrm{~V}, 1.0 \mathrm{~V}, 0.8 \mathrm{~V}$, and $0.7 \mathrm{~V}$ at $25{ }^{\circ} \mathrm{C},-100{ }^{\circ} \mathrm{C},-150{ }^{\circ} \mathrm{C}$, and $-170{ }^{\circ} \mathrm{C}$, respectively. At temperatures between $-170{ }^{\circ} \mathrm{C}$ and $-175{ }^{\circ} \mathrm{C}$, the device exhibits instability in performance in the form of intermittent loss of the output signal. Beyond $-175^{\circ} \mathrm{C}$, the device ceases to operate but recovers as soon as temperature is brought back to about $-170{ }^{\circ} \mathrm{C}$. This preliminary result indicates that the usefulness of the device depends on whether the shift in the control voltage signal with temperature is tolerable in the specific application or if some feedback compensation is provided to accommodate for these low temperature induced changes.

The performance of three precision oscillators was investigated at low temperatures. One uncompensated oscillator was able to function to $-196{ }^{\circ} \mathrm{C}$. A second uncompensated oscillator was built to operate at ultra-low temperatures, and it operated down to $-263{ }^{\circ} \mathrm{C}$. A third oscillator, which was temperature compensated and modified for low temperature use, operated within $0.3 \mathrm{ppm}$ in frequency down to $-160{ }^{\circ} \mathrm{C}$. The normalized output frequencies of the three oscillators are shown as a function of temperature in Figure 2.

Several DC/DC converters have been built and characterized, in-house, at low temperatures. The converters were designed or modified to operate from room temperature to $-196^{\circ} \mathrm{C}$ using commercially available components such as CMOS-type devices and MOSFET switches. These systems had output power range from $5 \mathrm{~W}$ to $1 \mathrm{~kW}$ with switching frequencies of $50 \mathrm{kHz}$ to $200 \mathrm{kHz}$. Pulse width modulation technique was implemented in most of these systems with open-loop as well as closed-loop control. The topologies included buck, boost, multi-resonant, push-pull and full-bridge configuration [8-11]. In addition, several commercially available DC/DC converter modules were investigated for potential use at low temperatures. The output voltage and efficiency of a commercial DC/DC converter at various load levels, for example, are shown as a function of temperature in Figures 3 and 4, respectively. It can be seen that the output voltage of this particular module tends to be steady only between $+20{ }^{\circ} \mathrm{C}$ and $-20{ }^{\circ} \mathrm{C}$. A slight reduction occurs in voltage regulation as temperature is further decreased to $-80{ }^{\circ} \mathrm{C}$. Beyond that temperature, the converter tends to become unstable in terms of voltage regulation. This behavior occurs regardless of the levels of the applied input voltage and connected output load. Similar trend is observed on the effect of low temperature on the efficiency of this converter.

The output voltage of another commercial converter module under the same test conditions is depicted in Figure 5. At low load levels, this converter exhibits excellent stability in its voltage regulation throughout the temperature range from $20{ }^{\circ} \mathrm{C}$ to $-120{ }^{\circ} \mathrm{C}$. At heavy loads, however, the converter output voltage tends to decrease with decreasing temperature. This decrease becomes more evident at temperatures lower than $-40{ }^{\circ} \mathrm{C}$. The efficiency of this converter is shown in Figure 6. In general, the efficiency drops as the temperature is lowered with the heavy load condition having a higher efficiency than that of a light load. It is important to note that although this converter ceases to operate beyond $-120^{\circ} \mathrm{C}$ it does, however, recover when the temperature is raised above that level.

Several temperature transducers were also characterized for their performance under extreme low temperatures. These two-terminal integrated circuit (voltage in/current out) temperature transducers produce an output current proportional to absolute temperature. In addition to temperature measurement, these devices can be used in applications that include flow rate measurements, correction of discrete components, temperature compensation, biasing proportional to absolute temperature, level detection of fluids, and anemometry.

The transducers were evaluated in terms of output response and linearity as a function of temperature. Characterization was performed in the temperature range of $293 \mathrm{~K}\left(+20^{\circ} \mathrm{C}\right)$ to $80 \mathrm{~K}\left(-193^{\circ} \mathrm{C}\right)$. The data were initially gathered at room temperature, then at successive test temperatures down to $80 \mathrm{~K}$, and again at room temperature after low temperature was completed. Each device was characterized in terms of its output current, which is proportional to absolute temperature, as a function of temperature and its input or supply voltage. The effect of temperature on the output characteristics of one of these devices is depicted in Figure 7. It can be seen that this device produced an output current that reflects true representation of the temperature variable to be measured at all levels of the input voltage in the range of 4 to $30 \mathrm{~V}$ but within the test temperature range of $293 \mathrm{~K}$ to $140 \mathrm{~K}$. Beyond $140 \mathrm{~K}$, the transducer continued to produce an output but it lacked accuracy as well as linearity. This effect of extreme low temperature exposure on the linearity of this transducer is illustrated in Figure 8 where the output current corresponding to a certain temperature is shown at various supply voltage levels. Once again, the non-linearity begins to show at temperatures around $140 \mathrm{~K}$ and it becomes more profound as the temperature is decreased further and at high supply voltage levels. It is important to note that although all of the temperature transducers tested exhibited changes, with varying degrees, in their output linearity with decreasing temperature, none underwent any catastrophic failure due to exposure to the low temperature environment. This is evident from the full recovery in performance exhibited by all the devices tested upon their thermal stabilization back to room temperature. 
An SOI (Silicon-On-Insulator) MOSFET and a standard MOSFET device were characterized in the temperature range of $+20^{\circ} \mathrm{C}$ to $-190^{\circ} \mathrm{C}$. Performance characterization was obtained in terms of their gate threshold voltage (VGS(th)), drain-to-source on-state resistance (RDS(on)), and drain current (ID) versus drain-to-source voltage (VDS) family curves at various gate voltages (VGS). These properties were obtained using a digital curve tracer. The test temperatures at which these devices were investigated were: $20^{\circ} \mathrm{C},-50{ }^{\circ} \mathrm{C},-75^{\circ} \mathrm{C},-100{ }^{\circ} \mathrm{C},-125^{\circ} \mathrm{C},-150^{\circ} \mathrm{C}$, $-175^{\circ} \mathrm{C}$, and $-190^{\circ} \mathrm{C}$. Limited thermal cycling testing was also performed on the devices. These tests consisted of subjecting the devices to a total of five thermal cycles between $+20^{\circ} \mathrm{C}$ and $-190^{\circ} \mathrm{C}$. A temperature rate of change of $10{ }^{\circ} \mathrm{C} / \mathrm{min}$ and a soak time at the test temperature of 10 minutes were used throughout this work.

Figure 9 shows the gate threshold voltage (VGS(th)) versus temperature for both devices. The gate threshold voltage for each device was measured at very small values of drain currents. These values of drain current (i.e. $250 \mu \mathrm{A}$ for the standard and $100 \mu \mathrm{A}$ for the SOI) were selected from each of the manufacturer's specification. As can be seen from Figure 9, both devices exhibit an increase in gate threshold voltage with decreasing temperature. The standard MOSFET device, which has a maximum specified gate voltage of $20 \mathrm{~V}$, registered a gate threshold voltage in the range of $3.03 \mathrm{~V}$ to $3.92 \mathrm{~V}$ from $20{ }^{\circ} \mathrm{C}$ to $-190{ }^{\circ} \mathrm{C}$. This corresponds to a normalized gate threshold voltage (VGS(th)/ VGS (max)) range of 0.152 to 0.196 . The SOI MOSFET device, which has a maximum specified gate voltage of $10 \mathrm{~V}$, required a gate threshold voltage in the range of $1.64 \mathrm{~V}$ to $2.21 \mathrm{~V}$ from $20{ }^{\circ} \mathrm{C}$ to $-190{ }^{\circ} \mathrm{C}$. This corresponds to a normalized gate threshold voltage range of 0.164 to 0.221 . Both devices are concluded to display comparable changes in their gate threshold voltage with change in temperature.

Figure 10 shows the drain-to-source on-state resistance (RDS(on)) versus temperature for the two devices. As seen from Figure 2, both devices show similar behavior in their on-state resistance with temperature. The on-state resistance of either device seems to decrease with decrease in temperature till about $-170{ }^{\circ} \mathrm{C}$. This trend, however, is reversed as the test temperature is decreased further as reflected by the slight increase in the on-state resistance of both devices. At any temperature, the SOI device exhibits a slightly higher on-state resistance than its standard counterpart.

\section{Conclusion}

An overview of the Low Temperature Electronics Program at the NASA Glenn Research Center was given. The research efforts are focused on developing selected, mission-driven, power systems and supporting technologies for low temperature operation. The on-going activities include dielectric and insulating material research and evaluation, development and testing of low temperature power components, and electronic system integration and demonstration. Other supporting research investigations comprise long-term reliability assessment of power devices and integrated circuits and the effects of low temperature exposure on device interconnect and packaging.

A description of the in-house low temperature test facilities for material testing and characterization, and component and system evaluation along with some preliminary experimental data were also presented. Coordination of the various research and development efforts with other agencies, academia, and the aerospace industry as well as the utilization of test facilities with the proper diagnostic and analytical tools will certainly contribute to meeting the needs of future space power and other electrical systems.

\section{REFERENCES}

[1] Gerber, S S, Patterson, R L, Ray, B, \& Stell, C 1996, Performance of a spacecraft DC/DC converter breadboard modified for low temperature operation, IECEC 96, 1, 592598.

[2] Kirschman, R K 1991, Low temperature electronic device operation", Symp. Electrochemical Society, 14.

[3] Dean, M, Foty D, Saks, N, Raider, S, \& Oleszel, G 1991, Low temperature microelectronics: opportunities and challenges, Proc. Symp. Low Temperature Electronic Device Operation, Electrochemical Society, 91,14, 25-37.

[4] Ray, B, Gerber, S S, Patterson, R L, \& Myers, I T 1995, Power control electronics for cryogenic instrumentation, Advances in Inst. and Control, 50, 1, Int. Soc. for Measurement and Control, 131-139.

[5] Kirschman, R K 1985, Cold electronics: an overview, Cryogenics, 25, 3, 115-122.

[6] Mueller, O 1989, On-resistance, thermal resistance and reverse recovery time of power MOSFETs at $77 \mathrm{~K}$, Cryogenics, 29, 1006-1014.

[7] Ray, B, Gerber, S S, Patterson, R L, \& Myers, I T 1995, $77 \mathrm{~K}$ Operation of a multi-resonant power converter, IEEE PESC'95 Record, 1, 55-60.

[8] Ray, B, Gerber, S S, \& Patterson, R L 1996, Low temperature performance of a full-bridge $\mathrm{DC} / \mathrm{DC}$ converter, IECEC 96, 1, 553-559.

[9] Ray, B, Gerber, S S, Patterson, R L, \& Myers, I T 1995 , Liquid nitrogen temperature operation of a switching power converter, Symp. on Low Temp. Electronics and High Temperature Superconductivity, 9, 345-352.

[10] Gerber, S S, Miller, T, Patterson, R L, \& Hammoud, A 1998, Performance of a closed-loop controlled high voltage DC/DC converter at cryogenic temperature, IECEC 98, 1, 1083-1092.

[11] Ray, B \& Patterson, R L 1995, Wide temperature operation of a PWM DC/DC converter, IEEE Industry Applications Society Conference, 971-976. 


\section{BIOGRAPHIES}

Richard Patterson has led the Low Temperature Electronics Program at the NASA Glenn Research Center since its inception in 1994. This program deals with the development of reliable and efficient electronic components and systems for use in extreme low temperature environments. His past experience has included instrumentation, $x$-ray

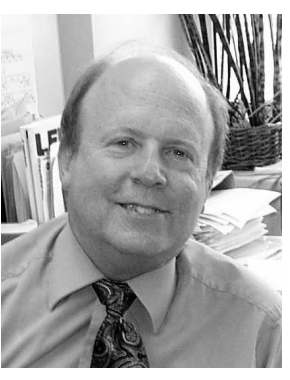
systems, electromagnetic pulse phenomena, electron optics, and nuclear rocket engine fuel development during his tenure at Bendix Research, Picker Corporation, General Electric, and Westinghouse. He holds a BS in Physics and an $M S$ in engineering administration. He has four patents, one $R \& D 100$ Award, and over 30 journal and conference publications.

Ahmad Hammoud received his B.S. (1982), M.S. (1984), and Ph.D. (1988) degrees in Electrical and Computer Engineering from the State University of New York at Buffalo. He currently holds the position of a Senior Electrical Engineer with QSS Group, Inc. providing technical services and managerial support to the Power

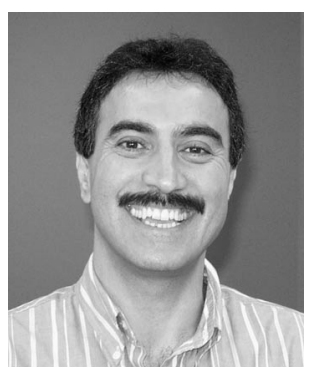
and On-Board Propulsion Division at the NASA Glenn Research Center in Cleveland, Ohio. His assignments involve engineering research and development, and program planning and management. His expertise includes advanced electrical components and power systems for aerospace environments, high performance insulation and dielectrics, and radiation and thermal effects on materials and devices.
John E. Dickman received B.S. (1969) Physics, University of Michigan; M.A. (1971) and Ph.D. Physics (1977), Wayne State University. He joined NASA in 1983 after 5 years in the semiconductor industry. He performed research in space communications and space power technologies at NASA Glenn Research Center. Dr. Dickman has 6 patents and over 30 journal and conference publications.

Scott Gerber is a Senior Electrical Engineer for ZIN Technologies, Inc. His areas of specialty include power electronics, dc-dc converter, motor drives and digital systems design. Presently, he is involved in the research and development of cryogenic electronics and Stirling engine controllers for NASA. In addition, he is designing commercial power supplies for the semiconductor/coatings industry. Scott received his BSEE in 1984 and his MSEE in 1988 from The University of Toledo. 


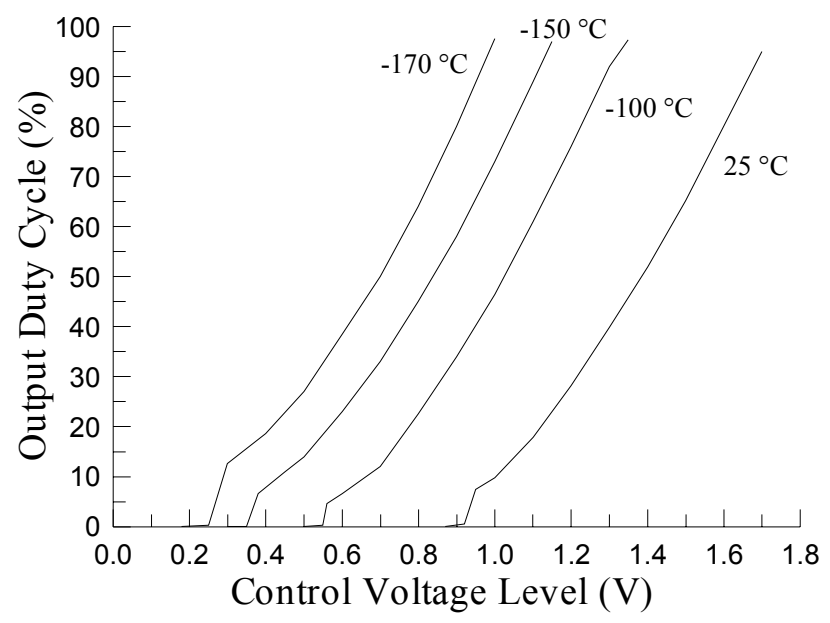

Figure 1.-Change in Duty Cycle with Control Voltage Level as a Function of Temperature.

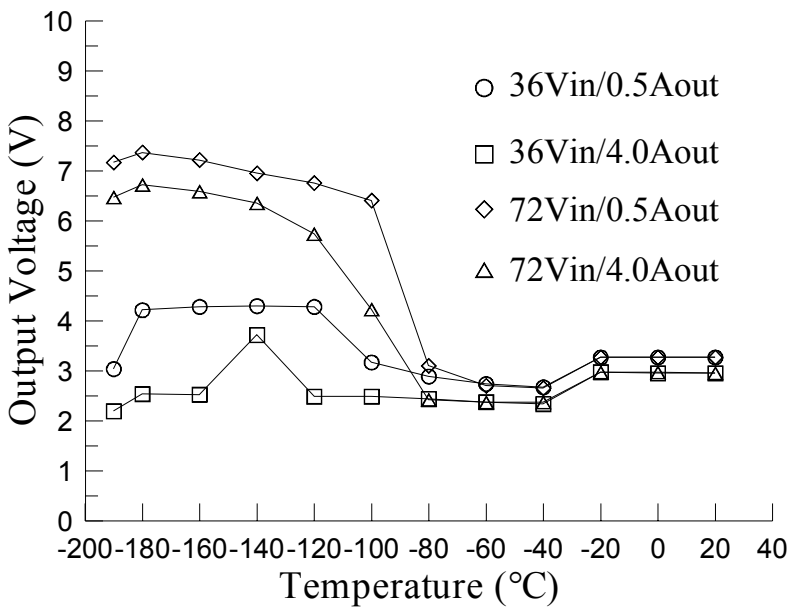

Figure 3.- Output Voltage of a DC/DC Converter Module as a Function of Temperature.

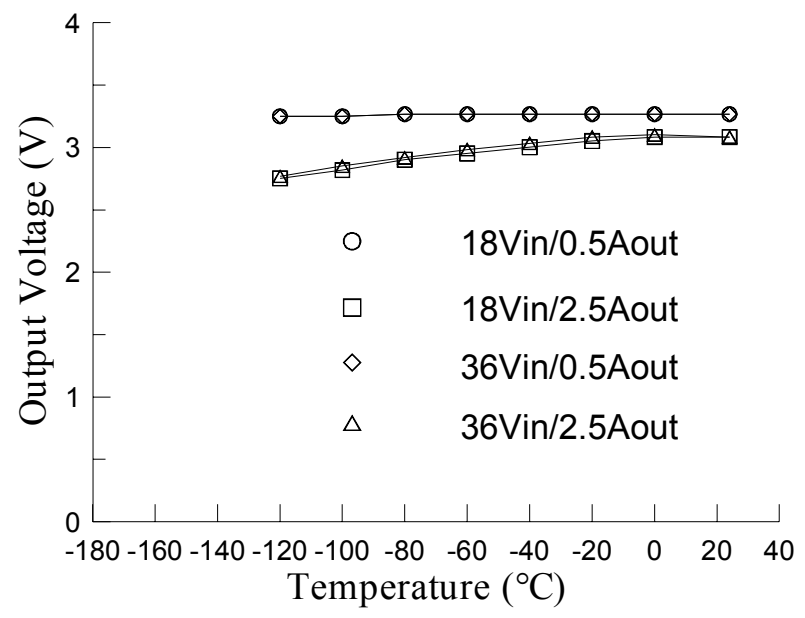

Figure 5.-Output Voltage of a DC/DC Converter Module as a Function of Temperature.

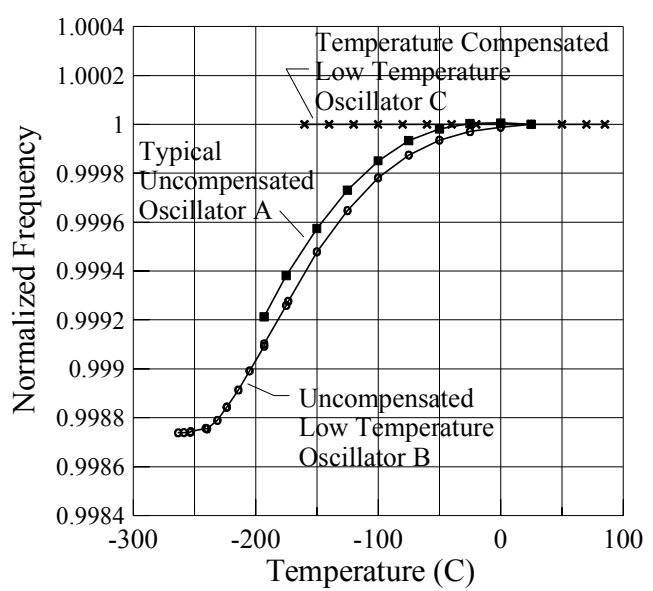

Figure 2.--Normalized Output Frequency for Three Oscillators at Low Temperatures

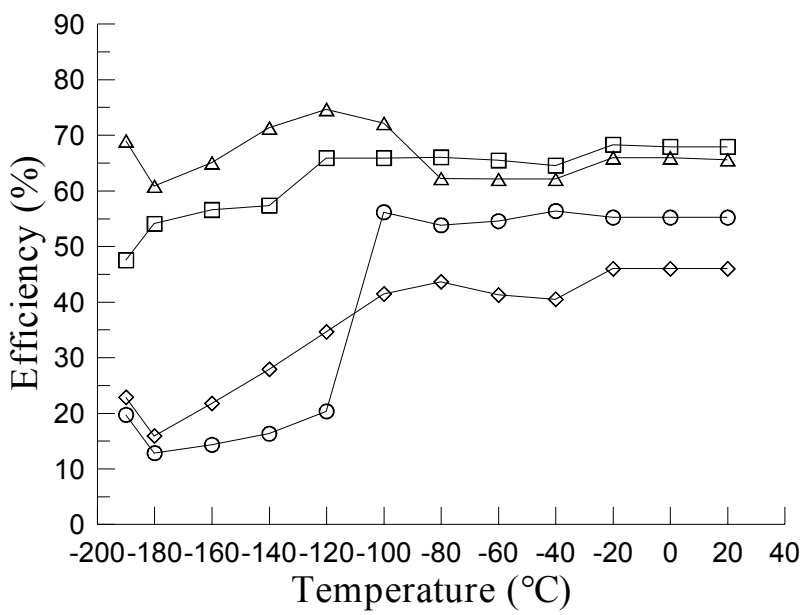

Figure 4.-Efficiency of DC/DC Converter Module As a Function of Temperature.

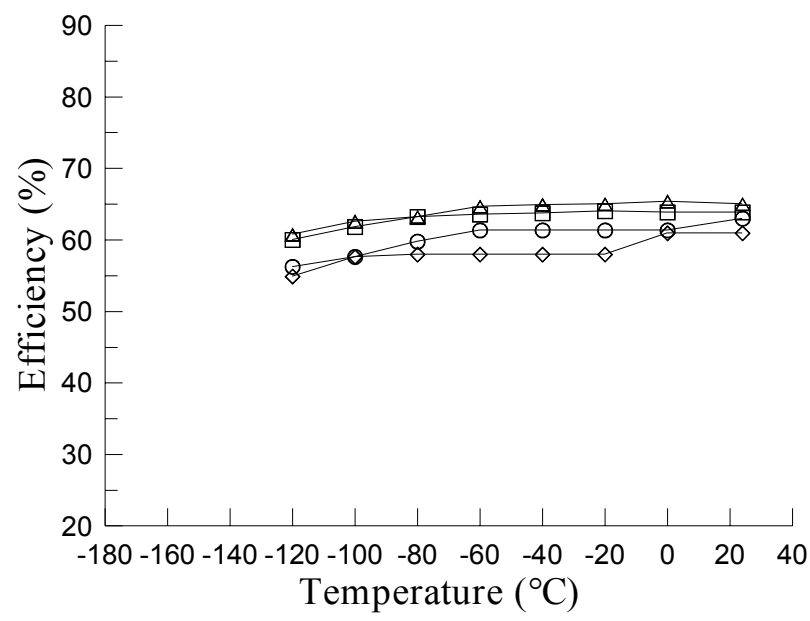

Figure 6. - Output Voltage of DC/DC Converter Module as a Function of Temperature. 


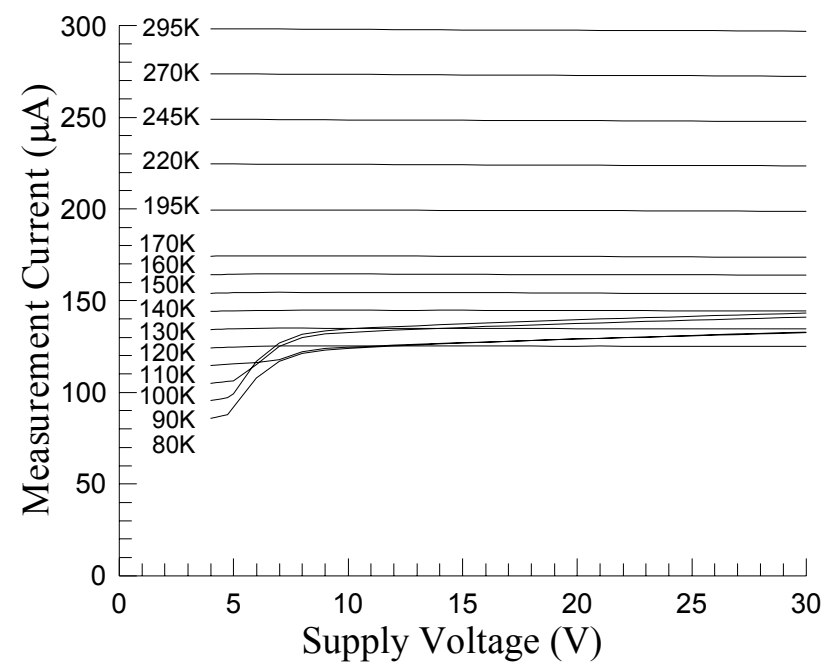

Figure 7.-Current-Voltage Characteristics at Various Temperatures for a Temperature Transducer.

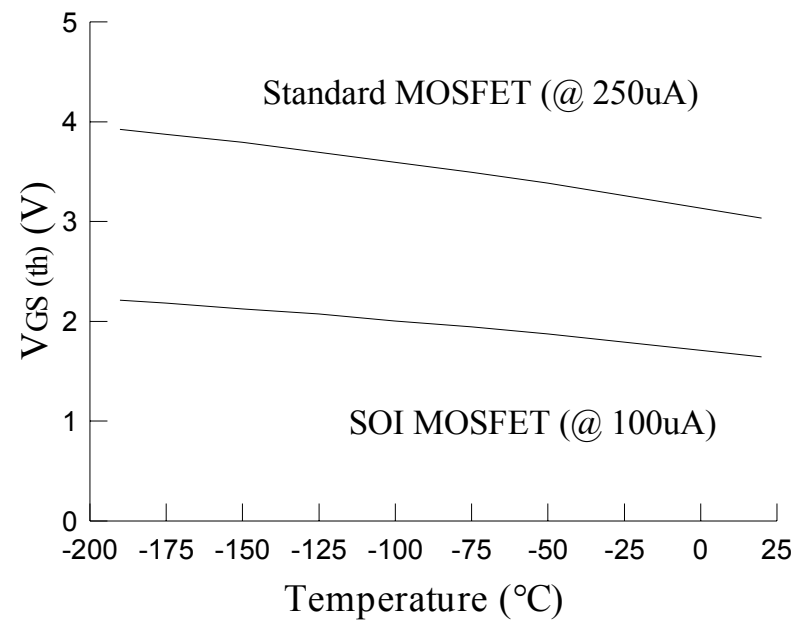

Figure 9.-Gate Threshold Voltage for SOI and Standard MOSFET Devices versus Temperature.

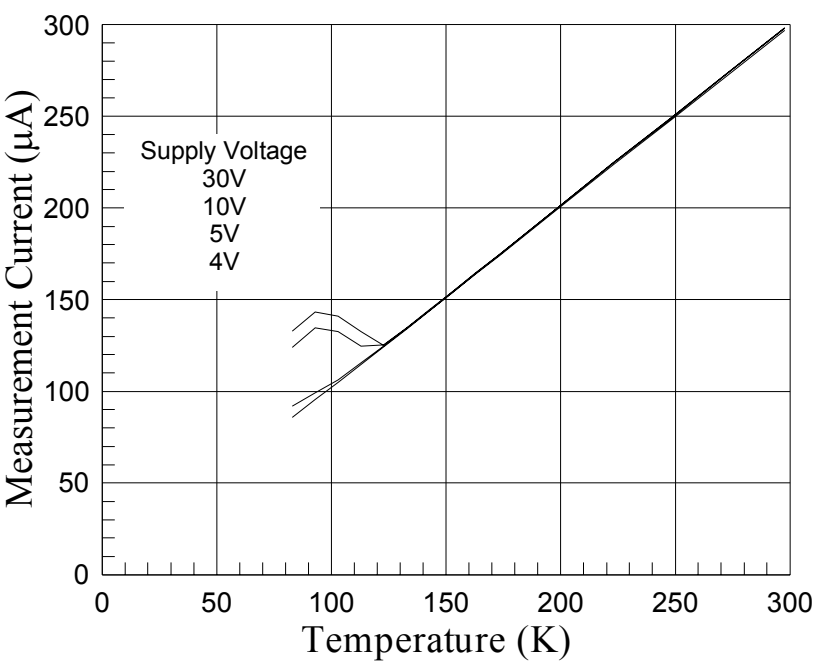

Figure 8.-Linearity Characteristics of a Temperature Transducer at Various Supply Voltages.

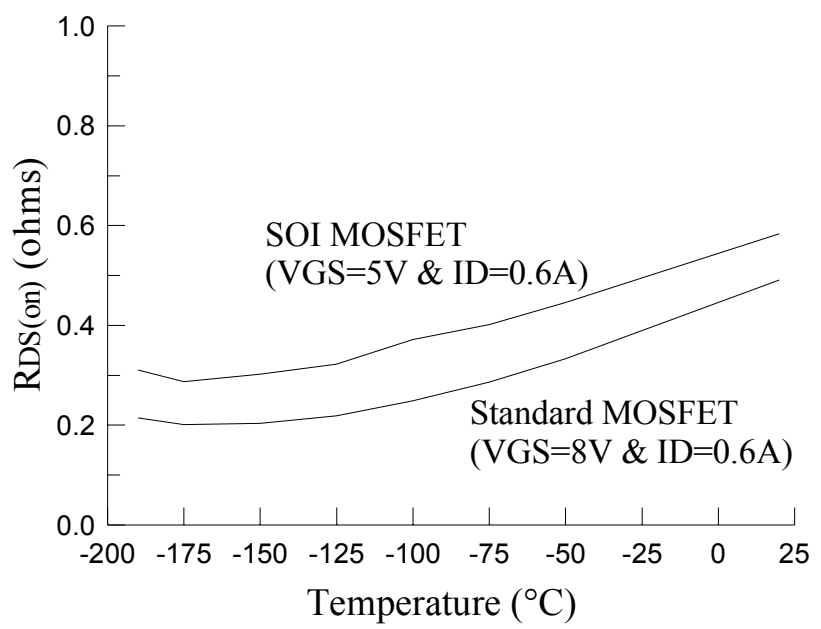

Figure 10.-Drain-to-Source On-Resistance for SOI and Standard MOSFET Devices versus Temperature. 
Public reporting burden for this collection of information is estimated to average 1 hour per response, including the time for reviewing instructions, searching existing data sources, gathering and maintaining the data needed, and completing and reviewing the collection of information. Send comments regarding this burden estimate or any other aspect of this collection of information, including suggestions for reducing this burden, to Washington Headquarters Services, Directorate for Information Operations and Reports, 1215 Jefferson Davis Highway, Suite 1204, Arlington, VA 22202-4302, and to the Office of Management and Budget, Paperwork Reduction Project (0704-0188), Washington, DC 20503.

\begin{tabular}{|l|l|l|}
\hline 1. AGENCY USE ONLY (Leave blank) & $\begin{array}{c}\text { 2. REPORT DATE } \\
\text { January } 2003\end{array}$ & $\begin{array}{r}\text { 3. REPORT TYPE AND DATES COVERED } \\
\text { Technical Memorandum }\end{array}$ \\
\hline
\end{tabular}

\section{TITLE AND SUBTITLE} 5. FUNDING NUMBERS

Electronic Components and Circuits for Extreme Temperature Environments

6. AUTHOR(S)

WBS-22-297-60-05

Richard L. Patterson, Ahmad Hammoud, John E. Dickman, and Scott Gerber

7. PERFORMING ORGANIZATION NAME(S) AND ADDRESS(ES)

National Aeronautics and Space Administration

John H. Glenn Research Center at Lewis Field

Cleveland, Ohio 44135-3191
8. PERFORMING ORGANIZATION REPORT NUMBER

E-13732

\section{SPONSORING/MONITORING AGENCY NAME(S) AND ADDRESS(ES)}

10. SPONSORING/MONITORING AGENCY REPORT NUMBER

National Aeronautics and Space Administration

Washington, DC 20546-0001

NASA TM-2003-212079

\section{SUPPLEMENTARY NOTES}

Prepared for the 2003 Aerospace Conference sponsored by the Institute of Electrical and Electronics Engineers, Big Sky, Montana, March 8-15, 2003. Richard L. Patterson and John E. Dickman, NASA Glenn Research Center; Ahmad Hammoud, QSS Group, Inc., Cleveland, Ohio 44135; Scott Gerber, ZIN Technologies, Inc., Cleveland, Ohio 44135. Responsible person, Richard L. Patterson, organization code 5480, 216-433-8166.

12a. DISTRIBUTION/AVAILABILITY STATEMENT

Unclassified - Unlimited

Subject Category: 76 12b. DISTRIBUTION CODE

Available electronically at http://gltrs.grc.nasa.gov

This publication is available from the NASA Center for AeroSpace Information, 301-621-0390.

\section{ABSTRACT (Maximum 200 words)}

Planetary exploration missions and deep space probes require electrical power management and control systems that are capable of efficient and reliable operation in very low temperature environments. Presently, spacecraft operating in the cold environment of deep space carry a large number of radioisotope heating units in order to maintain the surrounding temperature of the on-board electronics at approximately $20{ }^{\circ} \mathrm{C}$. Electronics capable of operation at cryogenic temperatures will not only tolerate the hostile environment of deep space but also reduce system size and weight by eliminating or reducing the radioisotope heating units and their associate structures; thereby reducing system development as well as launch costs. In addition, power electronic circuits designed for operation at low temperatures are expected to result in more efficient systems than those at room temperature. This improvement results from better behavior and tolerance in the electrical and thermal properties of semiconductor and dielectric materials at low temperatures. The Low Temperature Electronics Program at the NASA Glenn Research Center focuses on research and development of electrical components, circuits, and systems suitable for applications in the aerospace environment and deep space exploration missions. Research is being conducted on devices and systems for reliable use down to cryogenic temperatures. Some of the commercial-off-the-shelf as well as developed components that are being characterized include switching devices, resistors, magnetics, and capacitors. Semiconductor devices and integrated circuits including digital-to-analog and analog-to-digital converters, DC/DC converters, operational amplifiers, and oscillators are also being investigated for potential use in low temperature applications. An overview of the NASA Glenn Research Center Low Temperature Electronic Program will be presented in this paper. A description of the low temperature test facilities along with selected data obtained through in-house component and circuit testing will also be discussed. Ongoing research activities that are being performed in collaboration with various organizations will also be presented.

\section{SUBJECT TERMS}

Electronics; Space; Cryogenics

\section{NUMBER OF PAGES}

13

16. PRICE CODE

\begin{tabular}{|c|c|c|}
\hline $\begin{array}{c}\text { 17. SECURITY CLASSIFICATION } \\
\text { OF REPORT } \\
\text { Unclassified }\end{array}$ & $\begin{array}{c}\text { 18. SECURITY CLASSIFICATION } \\
\text { OF THIS PAGE } \\
\text { Unclassified }\end{array}$ & $\begin{array}{c}\text { 19. SECURITY CLASSIFICATION } \\
\text { OF ABSTRACT } \\
\text { Unclassified }\end{array}$ \\
\hline
\end{tabular}



